\title{
Effects of Sulpiride on True and False Memories of Thematically Related Pictures and Associated Words in Healthy Volunteers
}

\author{
Regina V. Guarnieri ${ }^{1 *}$, Rafaela L. Ribeiro ${ }^{1}$, Altay A. Lino de Souza ${ }^{2}$, \\ José Carlos F. Galduróz' ${ }^{1}$, Luciene Covolan ${ }^{3}$ and Orlando F. A. Bueno ${ }^{1}$ \\ ${ }^{1}$ Department of Psychobiology, Universidade Federal de São Paulo, São Paulo, Brazil, ${ }^{2}$ Associação Fundo de Incentivo à \\ Pesquisa, São Paulo, Brazil, ${ }^{3}$ Department of Physiology, Universidade Federal de São Paulo, São Paulo, Brazil
}

\section{OPEN ACCESS}

Edited by:

Michael Noll-Hussong,

University of UIm, Germany

Reviewed by:

Satoru Otani,

Ryotokuji University, Japan Nicola B. Mercuri,

University of Rome Tor Vergata, Italy

${ }^{*}$ Correspondence:

Regina V. Guarnieri

vguarnieri@uol.com.br

Specialty section: This article was submitted to Affective Disorders and

Psychosomatic Research, a section of the journal

Frontiers in Psychiatry

Received: 09 December 2015 Accepted: 19 February 2016

Published: 18 March 2016

Citation:

Guarnieri RV, Ribeiro RL, de Souza AAL, Galduróz JCF, Covolan L and Bueno OFA (2016) Effects of Sulpiride on True and False Memories of Thematically Related Pictures and Associated Words in Healthy Volunteers.

Front. Psychiatry 7:28. doi: 10.3389/fpsyt.2016.00028
Episodic memory, working memory, emotional memory, and attention are subject to dopaminergic modulation. However, the potential role of dopamine on the generation of false memories is unknown. This study defined the role of the dopamine $D_{2}$ receptor on true and false recognition memories. Twenty-four young, healthy volunteers ingested a single dose of placebo or $400 \mathrm{mg}$ oral sulpiride, a dopamine $\mathrm{D}_{2}$-receptor antagonist, just before starting the recognition memory task in a randomized, double-blind, and placebo-controlled trial. The sulpiride group presented more false recognitions during visual and verbal processing than the placebo group, although both groups had the same indices of true memory. These findings demonstrate that dopamine $D_{2}$ receptors blockade in healthy volunteers can specifically increase the rate of false recognitions. The findings fit well the two-process view of causes of false memories, the activation/ monitoring failures model.

Keywords: dopamine, dopamine $D_{2}$ receptor, sulpiride, true recognition, false recognition, amygdala

\section{INTRODUCTION}

Memory has a reconstructive nature, and new details of an experience can be incorporated into a memory trace during reconsolidation. During this process, the details can be forgotten, become distorted, or inaccurate (1). Moreover, in some cases, the memory can be totally false (2). Recognition tests involve two separate process, one often referred as remember response and characterized by recollective experience (episodic memory) and the other one due to a phenomenological experience of familiarity, in which the item is not consciously remembered to have been seen $(1,3)$.

Over the past decade, research conducted in the mental health field and in the legal field has suggested that emotion may play a role in the production of false memories. In these areas, the phenomenon of false memories has drawn attention because some studies have indicated that certain psychotherapeutic techniques, which are based on the recovery of emotional memories from childhood, can produce vivid memories of events that actually did not occur, such as alleged cases of sexual violence suffered in childhood (4). In the legal area, the impact of emotion on memory function may compromise the exercise of justice, as the person who witnessed a crime, offense, and/ or has been the victim of violence may be subject to distortions in their memories (5). 
False recognition, "the mistaken belief that one has previously encountered a novel item" as defined by Clancy et al. (6), is usually studied with versions of the Deese-Roediger-McDermott (DRM) paradigm, in which subjects study lists of words that are also related to a non-studied word, a lure that subjects often falsely recall or recognize as having been presented in the study list $(7,8)$. These authors state that at least two factors determine the likelihood by which a given studied material yields a true or false recollection, namely (a) an associative activation that spreads through the semantic system to non-studied items and (b) a monitoring failure by which distinctive features of nonstudied items are not recognized (8).

To evaluate false recognition for visual stimuli, pictures from the International Affective Picture System (IAPS) (9, 10), a widely used database that contains hundreds of complex realistic pictures, were organized in a way to facilitate false memory production in a task called DRM-IAPS (11). The emotional reaction to any stimulus (e.g., images and words) can be classified according to valence and arousal through the test named Self-Assessment Manikin (SAM) (12). The stimuli that trigger emotional reactions with low valence are described as negative, those with medium values of valence are described as neutral, and those with high valence are described as positive. It is also valid for the classification of arousal, when low levels of stimuli are classified as relaxed, average levels are classified as neutral, and high levels are classified as excited $(10,13)$.

It has long been observed that emotion enhances episodic memory performance (14-17). The effect of the emotional content of stimuli on true memories was shown in a study, in which emotional words were more vividly remembered than neutral ones (18). Emotion promotes better true memory performance compared to neutral events, probably due to increased attention, longer reverberation, better encoding, and elaboration of emotionally loaded stimuli $(16,19)$. High arousal words and photographs with positive or negative valence have a higher probability of being correctly retrieved compared to similar stimuli classified as neutral $(18,20,21)$.

On the other hand, the investigation of the influence of emotion on false memories has yielded some contradictory results. Pesta et al. (22) as well as Kensinger and Corkin (19) have found a decrease in false recognition of emotional events compared to neutral ones. Emotional salience would provide greater distinctiveness to the lures making them less likely to be confounded with true event, thus reducing the incidence of false memories. Otherwise, it has been reported that negative events increase the incidence of false memories to the highest level, neutral events to an intermediate level, and positive stimuli to the lowest level, probably due to a monitoring failure to suppress erroneous acceptance (23). It was also reported (24) that emotionally valenced words increase the tendency of false recollection of unstudied items (lures) due to their level of semantic cohesion. Similarly, it was suggested (25) that emotional load increases semantic relatedness, which in turn may contribute to increased false recollection. It has been reported (26) that emotional words (lures) elicited more positive event-related potentials than did neutral words, and the emotional distractors were falsely recognized more often than the neutral ones. Taken together, these results point to the idea that emotional stimuli are more salient and/or more semantically related than neutral stimuli, and these characteristics form the basis for false recognition effects.

Memory-impairing drugs, such as benzodiazepines [diazepam (27), triazolam (28), lorazepam (27), and alcohol (29-31)], and the anticholinergic drug scopolamine (32) have variable effects on false memory assessed by similar versions of the DRM task (33). Some of these drugs reduced false recognition of related and unrelated lures, while others did not affect false recognition of unrelated lures, and others had the opposite effect. In fact, the memory-enhancer dextroamphetamine (AMP) and the memory-impairing $\Delta$-9-tetrahydrocannabinol $(\Delta-9$-THC) affected false memory in comparison to placebo, although they had opposite effect on true memory, and AMP increased false recognition compared to $\Delta-9$-THC (33).

In spite of a wide literature about dopaminergic modulation of working memory and executive functions (34-36), few studies were aimed to evaluate the role of the dopaminergic system on episodic memory in healthy subjects (37-41). Activation of the dopaminergic system enhances learning and memory formation $(38,41)$. There is some evidence that blocking dopamine $\mathrm{D}_{2}$ receptors impairs declarative memory (40). Plenty of work, both in animals and humans, recognize that the dopaminergic system plays a regulatory role for emotional, motivational, cognitive, and executive functions (42-44). More recently, the role of the dopaminergic system in the process by which the frontal lobe and the striatum control decision-making processes was described (45). Identification of a prior occurrence that happened during recognition depends on decision-making processes.

There is evidence that dopamine modulates the responses of the amygdala to sensory information in Parkinson's disease patients (46), a finding consistent with findings in experimental animals (47).

We are not aware of studies that aimed to investigate the dopamine $\mathrm{D}_{2}$ receptors blockade effects on false memory. If $\mathrm{D}_{2}$ dopaminergic receptors modulate the amygdala response to emotional stimuli or either is involved in frontal executive and working memory, we predict that blocking the dopaminergic $\mathrm{D}_{2}$ receptor system would affect false recognition. As yet, there is no evidence of the role of a $\mathrm{D}_{2}$ antagonist on false memories; here, we evaluate the effects of sulpiride, a selective dopamine $\mathrm{D}_{2}$ receptor antagonist on two emotional visual (DRM-IAPS) and verbal (DRM) tasks.

\section{MATERIALS AND METHODS}

\section{Participants}

The subjects were healthy young male university students. Females were excluded from the study due to the possible side effects of sulpiride, such as galactorrhea with hyperprolactinemia, gynecomastia, breast tenderness, and menstrual irregularity, caused by the action of the drug in the tuberoinfundibular pathway. They were also excluded due to greater emotional variability than men caused by hormonal fluctuations. The subjects were non-smokers with no history of drug abuse, alcoholism, and neurological, psychiatric, or sleep disorders. The subjects' body mass indices (BMIs) were within the normal range $\left(18-25 \mathrm{~kg} / \mathrm{m}^{2}\right)$. They were also not on prescription drugs. The 
participants were matched according to age, education (years of schooling), and intelligence quotient (IQ) measured with the Raven's Progressive Matrices (48).

The study was approved by the local Ethics Committee (No. CEP 2020/09), and all participants provided written consent according to the Ethics Committee of the Universidade Federal de São Paulo.

\section{Design and Materials}

Twenty-four healthy, young male volunteers were orally administered sulpiride, $400 \mathrm{mg}(n=12)$ or placebo (lactose; $n=12$ ).

\section{Procedure}

One week before the experiment, the participants completed the Raven's Matrices tasks from the State-Trait Anxiety Inventory (STAI) $(49,50)$ as well as physical, clinical, and psychiatric questionnaires. At the screening, seven candidates were excluded and replaced by other subjects (two had high anxiety levels, two had high BMI, two had low IQ scores, and one subject was a smoker). On the day of the experiment, the volunteers ate a controlled breakfast (free of tryptophan, tyrosine, and caffeine) and then completed the STAI. Following the test instructions, the volunteers ingested the capsules at 7:45 a.m. The memory tasks were performed $3 \mathrm{~h}$ after capsule ingestion (sulpiride serum peak). This is the time window necessary to afford sensitivity to cognitive modulation (51). The participants returned home after completing the memory task by taxi.

\section{Mood Task}

The STAI verified the subjects' baseline anxiety levels (scores above 40 were excluded) 1 week before the experiment and again on the day of the experiment at the beginning $\left(T_{1}\right)$ and the end $\left(\mathrm{T}_{2}\right)$ of the trial.

\section{Affective Rating Scale Self-Assessment Manikin}

The SAM is a non-verbal pictorial assessment technique that directly measures the pleasure, arousal, and dominance associated with a person's affective reaction to a wide variety of stimuli. It is an instrument used for subjective evaluation of emotions (12). The person subjectively evaluates the stimuli as to the valence (pleasure-displeasure) and arousal (relaxing-exciting) dimensions immediately after encoding each photo from 20 blocks ( 6 photos/block) during the study phase (encoding) of the DRM-IAPS task (see below). The participant should select the SAM man doll representing their subjective perception (greater or lesser extent) referring to visual stimuli presented.

The representation of the dimension of pleasure-displeasure of SAM ranges from a drawing of a smiling man doll at one end to a miserable sad man doll in the other. For the arousal dimension, the designs vary from stimulated and alert man doll to a relaxed and calm man doll. The subject should place an "X" on each of the scale drawings or between two subsequent drawings resulting in a scale from 1 to 9 . The value " 1 " represents the lowest score in each dimension, that is, little pleasure/little arousal, whereas the value " 9 " is the highest score in each dimension, that is, high pleasure/high arousal.

\section{Memory Tasks}

\section{Story Recall: Logical Memory}

The logical memory test consists of a story used in clinical practice as a tool for verbal memory assessment. The story contains 26 unit-ideas, each one equivalent to an item. The unit-idea may consist of one or more words, e.g., along the story line the name of a person (Ana Soares) is presented and it is one unit-idea. The experimenter reads the story in a loud voice, and the individual is asked to recall immediately after the presentation (immediate recall) and $30 \mathrm{~min}$ after the presentation (delayed recall). Subject score consists on the sum of exact recall of all the items, with the maximum of 26 items [WMS-R (52)].

\section{Deese-Roediger-McDermott Procedure}

This is a recognition test that associates words with neutral and emotional content $(7,53,54)$. In this study, were chosen 15 lists (each one contained 15 words) that had the highest rates of false recognition at Stein study. The word lists comprised four positive (music, fruit, sweet, and sleep), four neutral (chair, cold, pen, and high), and seven negative (thief, trash, smoke, needle, grief, pain, and fear) lists.

The presentation order of the words was randomly generated and varied for each subject. The participants were instructed to encode all lists. The words of each list revolve around a theme in which it is strongly associated. These words were termed critical keywords [e.g., smoke (critical word), for which associated words that belong to a common theme are cigarette, puff, blaze, billows, pollution, ashes, cigar, chimney, fire, tobacco, stink, pipe, lungs, flames, and stain] that were the related lures.

The recognition task was carried out immediately after presentation of the 15 lists. The recognition task consisted of 90 words, of which 45 of them were targets, 15 related lures, and 30 unrelated lures. The targets are the studied words in the original material taken from positions 1,8 , and 10 of the lists (hit rates); the related lures were words not presented in the original material but represent the semantic essence of each of the lists (false alarm); and the unrelated lures were words not presented in the original material that have no semantic relationship with them (response bias measured by items intrusions) (55). The subjects were asked to circle the words, presented in a sheet of paper that they thought to have seen before. If they circle a target, the measure is considered a "hit rate" and if they circle a related lure, it is considered a "false alarm." All subjects received the same test sheet. The complete lists are shown in Table 1.

\section{DRM-IAPS Task}

It was adapted by Pinto et al. (11) and based on the DRM test commonly used in false recognition studies $(7,56)$. The building set of associated images was extracted from the International Affective Picture (IAPS) (9) database, which is a widely used database that contains hundreds of complex, realistic pictures. The IAPS was standardized for the Brazilian population (10). The images contain hundreds of color photographs that can induce many emotional states. The two primary dimensions are affective valence (ranging from pleasant to unpleasant) and arousal (ranging from calm to excited). Of the 20 blocks, 5 are neutral (abstract figures, mushrooms, men, housewares, and clouds), 8 are positive 
TABLE 1 | Within-list words presented in this order.

DRM task - English equivalents of associated words lists used in this study, originally in Portuguese

\begin{tabular}{|c|c|c|c|c|c|c|c|}
\hline \multicolumn{7}{|c|}{ Negative } & \\
\hline Thief & Trash & Smoke & Needle & Hurt & Pain & Fear & \\
\hline Robbery & Dirt & Cigarette & Seam & Sadness & Suffering & Dark & \\
\hline Prison & Recycling & Addiction & Row & Feeling & Bruise & Death & \\
\hline Assault & Stink & Cancer & Thin & Tear & Loss & Loneliness & \\
\hline Police & Leftover & Harmful & Needle tip & Rancor & Crying & Anguish & \\
\hline Jail & Tin & Lung & Pierce & Deception & Nuisance & Panic & \\
\hline Dishonest & Bag & Drug & Injection & Disillusion & Wound & Scare & \\
\hline Robber & Pollution & Horrible & Syringe & Frustration & Remedy & Unknown & \\
\hline Insecurity & Organic & Cigar & Stick & Forgotten & Tooth & Dread & \\
\hline Money & Dry & Cough & Knitting & Annoying & Head & Violence & \\
\hline Theft & Waste & Nicotine & Embroider & Bitterness & Missing & Phobia & \\
\hline Poverty & Problem & Marijuana & Haystack & Mark & Blood & Cry & \\
\hline Revolver & Rotten & Ash & Machines & Attitude & Accident & Terror & \\
\hline Escape & Basket & Lighter & Metal & Infidelity & Analgesic & Trauma & \\
\hline Corruption & Disposable & Swallow & Yarn & Melancholy & Unbearable & Tremor & \\
\hline Delinquent & Collection & Tobacco & Nailing & Shortage & Desperation & Fear & \\
\hline \multicolumn{4}{|c|}{ Positive } & \multicolumn{4}{|c|}{ Neutral } \\
\hline Music & Fruit & Sleep & Sweet & Chair & Cold & Pen & High \\
\hline Sound & Healthy & Dream & Sugar & Sit & lce & Write & Low \\
\hline Dance & Apple & Bed & Yummy & Table & Winter & Ink & Building \\
\hline Disk & Vitamin & Rest & Chocolate & Wood & Coat & Blue & Large \\
\hline Rhythm & Banana & Wake & Flavor & Object & Snow & Paper & Long \\
\hline Melody & Strawberry & Nightmare & Honey & Convenience & Blanket & Helpful & Edifice \\
\hline Singer & Juice & Essential & Ice cream & Room & Sweater & Notebook & Sky \\
\hline Lyrics & Orange & Accompanied & Delight & Swings & Blouse & Communication & Imposing \\
\hline Radio & Mature & Lying & Candy & Furniture & Coziness & Ballpoint & Far away \\
\hline Guitar & Pear & Energy & Snack & Backrest & Temperature & Case & Distant \\
\hline Instruments & Nutritious & Early & Dainty & Class & Heat & Proof & Stature \\
\hline Notes & Watermelon & Nap & Diabetes & Upholstered & Chill & Scratch & Difficult \\
\hline Harmony & Juicy & Hammock & Fat & Support & Rain & Signature & High \\
\hline Listen & Grape & Silence & Caries & Armchair & Wool & Cap & Size \\
\hline Voice & Salad & Afternoon & Pie & Bench & Fireplace & Letter & Thin \\
\hline Electric guitar & Peach & Gape & Taste & Decoration & Soup & Material & Giant \\
\hline
\end{tabular}

Words were translated to English; for the words in Portuguese, see Stein et al. (54). The lists were randomly presented, so the order of presentation changed from subject to subject.

(food, sports, extreme sports, sex, couples, mountain, babies, and family), and 7 are negative (guns, fierce animals, snakes, mutilated bodies, disfigured faces, violence, and car accidents). Each photograph had the level of arousal and valence determined in previous studies (10) with means calculated for each of the 20 blocks.

The recognition task consisted of two stages:

Study phase (encoding): 120 photos were grouped into 20 sets of 6 thematically related pictures. Each set had a main theme (e.g., sex, guns, or abstract figures). The participants were shown pictures ordered by sets photo by photo, for $3 \mathrm{~s}$ each with an inter-stimulus interval of $1 \mathrm{~s}$.

Test phase (recognition): within each six-picture set, three pictures were presented again (targets), two were new pictures (related lures), and one picture was not related to any of the sets from test phase but had the same valence and awareness set level (unrelated lures). The recognition task was performed $1 \mathrm{~h}$ later, and the participants were shown 120 pictures (60 targets, 40 related lures, and 20 unrelated lures) in a random order. Each picture was presented for $4 \mathrm{~s}$, with a 3-s inter-stimulus interval.
The participants were asked to say, for each picture, "Yes" if they thought they had seen it before (in the study phase) or "No." The picture sets had been standardized for thematic, perceptual, and emotional similarity with a large, representative sample (11).

This method of organizing stimuli into thematically related sets was inspired by previous research with words, which produced robust false recognition effects (23). As with the word lists routinely used in false memory studies $(7,56)$, the picture sets used here had been standardized for thematic, perceptual, and emotional similarity with a large, representative Brazilian sample (11). In addition, pictures in each set were ranked such that two pictures with a similar score in each set theme were chosen as related lures (to increase the chances of eliciting false recognition responses).

\section{Memory Data Analysis}

This was a randomized, double-blind, and placebo-controlled study. BMI, age, education, IQ, anxiety level, and SAM were analyzed by one-way ANOVA. Memory tasks (DRM and DRMIAPS) were analyzed with a three-way ANOVA $(2 \times 2 \times 3)$ with 
the factors of group (placebo/sulpiride), item (target/lures), and valence (positive/negative/neutral) using Fisher post hoc tests. Story recall (WMS-R) was analyzed with a repeated-measures ANOVA. Partial eta-square $\left(\eta_{\mathrm{p}}^{2}=\mathrm{SSeffect} / \mathrm{SSeffect}+\right.$ SSerror $)$ were performed to evaluate the effect size (approximately 0.01 - small, approximately 0.06 - medium, and $>0.14$ - big effect) $(57,58)$. Differences were considered significant when $p<0.05$.

\section{RESULTS}

The participant characteristics were not significantly different between groups (Table 2).

\section{Mood Effects (STAI)}

There was no effect of group on anxiety (STAI-state) before tpre $\left._{(22)}: 0.19 ; p=0.85\right]$ or after the recognition task [post $_{(22)}$ : $-0.49 ; p=0.62$ ] (Student's $t$-test). There was no evidence of major differences in anxiety between sulpiride and placebo participants (Table 3).

\section{Self-Assessment Manikin}

Differences between groups were observed for emotional evaluation of stimuli, specifically the subjective judgment of pleasure on the block about sex (positive valence) $\left[F_{(1,22)}=6.77 ; p=0.016\right]$ and about disfigured faces (negative valence) $\left[F_{(1,22)}=5.25 ; p=0.032\right]$. The sulpiride group judged the block about sex as being more pleasant and the block about disfigured faces as more unpleasant than did the placebo group.

\begin{tabular}{|c|c|c|c|}
\hline \multirow[t]{2}{*}{ Variable } & Sulpiride & Placebo & $p$-value \\
\hline & Mean (SD) & Mean (SD) & \\
\hline \multicolumn{4}{|l|}{ Participant characteristics } \\
\hline Age (years) & $24.58(4.19)$ & $23.92(4.70)$ & 0.717 \\
\hline Body mass index (kg/m²) & $24.56(1.45)$ & $24.32(3.57)$ & 0.832 \\
\hline Education (years) & $15.92(1.45)$ & $14.92(2.78)$ & 0.289 \\
\hline Raven's matrices (percentile) & $88.00(16.69)$ & $86.08(15.68)$ & 0.774 \\
\hline
\end{tabular}

No. of male participants: 12/group. Number is expressed as mean $\pm S D$. $p<0.05$.

TABLE 3 | Sulpiride effects on anxiety and episodic memory recall.

\begin{tabular}{lcccc}
\hline Variable & Sulpiride & & Placebo & p-value \\
& Mean (SD) & & Mean (SD) & \\
\hline State-trait anxiety inventory & & & \\
$\quad$ STAl_state (pre) & $31.83(4.06)$ & & $32.33(8.04)$ & 0.850 \\
$\quad$ STAl_state (post) & $35.08(4.85)$ & & $37.75(7.87)$ & 0.622 \\
Episodic memory performance & & & \\
$\quad$ Story recall (number of unit-idea & & & \\
$\quad$ recalled) & & & \\
$\quad$ Immediate & $14.33(3.23)$ & & $17.50(3.55)$ & \\
$\quad$ Delayed & $13.33(2.74)$ & $15.25(4.18)$ & \\
\hline
\end{tabular}

Maximum numbers of items in the story recall $=26$; number is expressed as mean $\pm S D$.

$p<0.05$.
Regarding subjective feelings of arousal, the sulpiride group judged the block about mutilated bodies (negative valence) as producing a higher level of arousal than did the placebo group $\left[F_{(1,22)}=5.06 ; p=0.035\right]$.

\section{Story Recall}

The repeated-measures ANOVA revealed no differences between the groups $\left[F_{(1,22)}=3.57 ; p=0.07\right]$, but demonstrated that there were differences in time $\left[F_{(1,22)}=13.64 ; p=0.001\right]$, with no interaction between both factors $\left[F_{(1,22)}=2.01 ; p=0.16\right]$ (Table 3).

\section{DRM (\% Word Recognition)}

The ANOVA $(2 \times 2 \times 3)$ design revealed an effect for the three-way interaction $\left[F_{(2,44)}=4.17 ; p=0.022 ; \eta_{\mathrm{p}}^{2}=0.16\right]$ (Figure 1). Figure 1 shows the three-way effect between groups. Strong differences were found for lures on positive lists $(p=0.0004)$. Moreover, higher false alarm rates were found in the sulpiride group than in the placebo group for all valences (Table 4).

The groups had different false recognition for the unrelated lures on positive lists $\left[F_{(1,22)}=4.76 ; p=0.04\right]$ and negative lists $\left[F_{(1,22)}=9.96 ; p=0.004\right]$. As expected, no differences between the groups were found on the neutral lists $\left[F_{(1,22)}=2.92 ; p=0.10\right]$ (Table 5).

\section{DRM-IAPS (\% Pictures Recognition)}

The ANOVA $(2 \times 2 \times 3)$ design revealed an item $\times$ valence interaction $\left[F_{(2,44)}=114.47 ; p=0.001\right]$, as well as a three-way interaction (group $\times$ item $\times$ valence) $\left[F_{(2,44)}=4.95 ; p=0.01\right]$ (Figure 2$)$.

The groups performed similarly on true memories ( $p$-values $>0.05$ ). Interactions between items and groups were found for false recognition of negative pictures $(p<0.05)$ and approached

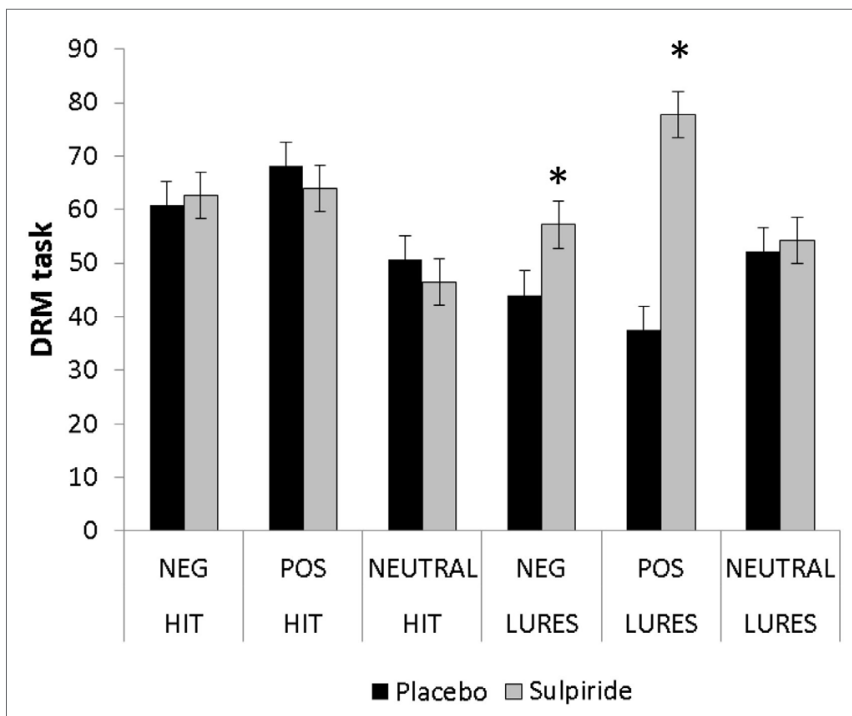

FIGURE 1 | Percentage of true and false recognition in the DRM paradigm comparing the sulpiride and placebo groups. Error bars are SEMs; ${ }^{*} p<0.05$. 
TABLE 4 | Percentage of true and false recognition in DRM-IAPS and DRM tasks.

\begin{tabular}{|c|c|c|c|c|c|c|}
\hline \multirow[t]{3}{*}{ Groups } & \multicolumn{3}{|c|}{ Hit rate $(\%)$} & \multicolumn{3}{|c|}{ False alarm rate $(\%)$} \\
\hline & \multicolumn{6}{|c|}{ DRM paradigm } \\
\hline & Positive lists & Neutral lists & Negative lists & Positive lists & Neutral lists & Negative lists \\
\hline Placebo & $68.06(4.79)$ & 50.69 (8.24) & $60.71(5.21)$ & $37.50(6.53)$ & 52.08 (7.82) & $44.05(4.11)$ \\
\hline \multirow[t]{3}{*}{ Sulpiride } & $63.89(6.01)$ & $46.53(6.11)$ & $62.70(5.37)$ & $77.08(6.50)^{\star}$ & 54.17 (6.02) & $57.14(7.25)^{\star}$ \\
\hline & \multicolumn{6}{|c|}{ DRM-IAPS paradigm } \\
\hline & Positive pictures & Neutral pictures & Negative pictures & Positive pictures & Neutral pictures & Negative pictures \\
\hline Placebo & 88.89 (2.68) & $84.44(2.07)$ & $91.67(2.12)$ & $28.65(6.08)$ & $45.00(6.22)$ & $35.12(5.73)$ \\
\hline Sulpiride & $89.24(2.88)$ & $85.00(2.48)$ & 91.27 (3.09) & $43.23(6.08)^{\#}$ & $53.33(5.55)$ & $59.52(6.72)^{\star}$ \\
\hline
\end{tabular}

Data are expressed as mean \pm SEM; * $p<0.05$, " $p=0.07$. Hit rate: to say "yes" to target; false alarm rate: to say "yes" to related lures.

DRM: positive lists: 12 targets and 4 related lures; neutral lists: 12 targets and 4 related lures; and negative lists: 21 targets and 7 related lures.

DRM-IAPS: total number of blocks: 20 (being 8 positive, 7 negative, and 5 neutral blocks). Positive pictures: 24 targets and 16 related lures; neutral pictures: 15 targets and 10 related lures; and negative pictures: 21 targets and 14 related lures.

TABLE 5 | Percentage of false recognition of unrelated lures DRM-IAPS and DRM tasks.

\begin{tabular}{|c|c|c|c|c|c|c|}
\hline \multirow[t]{3}{*}{ Groups } & \multicolumn{6}{|c|}{ False recognition of unrelated lures (\%) } \\
\hline & \multicolumn{3}{|c|}{ DRM paradigm } & \multicolumn{3}{|c|}{ DRM-IAPS paradigm } \\
\hline & Positive lists & Neutral lists & Negative lists & Positive pictures & Neutral pictures & Negative pictures \\
\hline Placebo & $6.67(2.84)$ & $5.88(2.29)$ & $17.71(2.86)$ & 11.46 (3.91) & $5.00(2.61)$ & $7.14(2.78)$ \\
\hline Sulpiride & $21.67(6.26)^{\star}$ & $14.22(4.31)$ & $39.58(6.31)^{\star}$ & $10.42(2.08)$ & $3.64(2.34)$ & $8.33(2.76)$ \\
\hline
\end{tabular}

Number of blocks: DRM-IAPS - positive pictures: 8; neutral pictures: 5; and negative pictures: 7. DRM - positive lists: 5; neutral lists: 7; and negative lists:

8. Data are expressed as mean \pm SEM.

${ }^{*} p<0.05$

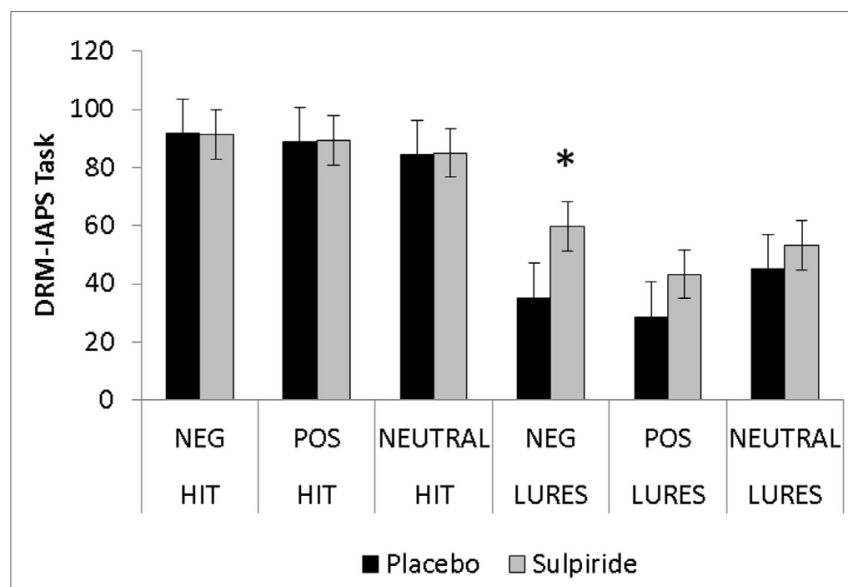

FIGURE 2 | Percentage of true and false recognition in the DRM-IAPS paradigm comparing the sulpiride and placebo groups. Error bars are SEMs; ${ }^{*} p<0.05$.

significance on positive pictures $(p=0.07)$ but not on false recognition of neutral stimuli ( $p=0.29$ ) (Table 4).

No differences between groups were found on false recognition of unrelated lures on positive pictures $\left[F_{(1,22)}=0.05\right.$; $p=0.82]$, negative pictures $\left[F_{(1,22)}=0.09 ; p=0.76\right]$, or neutral pictures $\left[F_{(1,22)}=0.001 ; p=1.00\right]$ (Table 5). In our study, both groups similarly recognized unrelated lures as not seen before in the DRM-IAPS $(p>0.05)$ but not in the DRM task $(p<0.05)$ (Table 5).

\section{DISCUSSION}

The present study showed that dopamine $\mathrm{D}_{2}$ receptor blockade by sulpiride, a dopamine $\mathrm{D}_{2}$ receptor antagonist, could specifically affect incorrect responses in recognition memory tasks. Sulpiride increased false recognition of related lures (false alarms in both DRM and DRM-IAPS tasks) and also increased false recognition of unrelated lures (intrusion) on DRM task. These increased intrusions were observed just on DRM but not DRM-IAPS, possibly because visual items from DRM-IAPS present more distinctiveness than verbal ones.

Effects on true memory were not observed either on story recall, DRM, or DRM-IAPS tasks. Perhaps, false recognition measures are sensitive to the drugs' effects than the standard hit rate measures. Ballard et al. (55) demonstrated that amphetamine did not affect emotional and non-emotional true memories but increased false recognition and recall intrusions, an interesting result because amphetamine is a non-selective catecholaminergic agonist. It seems that the mechanisms underlying the false memories are more susceptible to the action of drugs than true memories. On the contrary, Howe et al. (59) proposes that false memories are stronger than true ones; whereas true memories decline over time, false memories actually increase. Howe argued that it may be due to the different ways which they are formed. False memories tend to be self-generated as thought or imagination (generated by internal semantic activation). On the contrary, true memories are information that come from outside world and are often out-generated (words in a list or images used during the experimental task). Thus, in spite we agree with the 
above-mentioned authors about the different nature of true and false memories and its vulnerabilities; based on our current findings, we propose that false memories are more susceptible to drug effects than the true ones. The mechanisms underlying such differences, however, still remain to be elucidated.

According to some authors, failures during two processes may contribute to cause the DRM illusion: activation and monitoring processing $(8,56)$. Activation process failures may be due to increasing interference by overlapping features of memory traces, thus creating confusion between stimuli. Monitoring is described as any memory editing or decision process that helps to determine the origins of the activated information. Failures at monitoring process may also contribute to false recognition, which involves wrong diagnostic decisions to qualify or disqualify information as true (56). Therefore, the activation-monitoring framework (8) predicts that activating similar emotional reactions by related lures or a failure to monitor encoding or retrieval processes determine the propensity to create false memories. It suggests that the increased false recognition observed in the sulpiride group may have been due to the dopamine $\mathrm{D}_{2}$ receptors role in activating/ monitoring processes. One possibility is that sulpiride produces impairment on monitoring processing leading the subjects to confound studied and non-studied items.

The dopaminergic system is widely recognized as playing an important role in executive function and working memory and therefore in monitoring mechanisms of cognitive and behavioral functions. Dopamine $\mathrm{D}_{1}$ receptors activation of prefrontal cortex is necessary for working memory as seen in monkeys $(60,61)$ and humans $(62,63)$. However, not only dopamine $D_{1}$ receptors are involved in working memory but also dopamine $\mathrm{D}_{2}$ receptors. It has been shown that $\mathrm{D}_{2}$ receptor antagonists impair working memory and executive functions (34-36), as well as attention (64-66) in humans.

The prefrontal cortex is the primary mediator of working memory, but the distribution of dopamine $\mathrm{D}_{2}$ receptors in this area is limited, but abundant in striatum and hippocampus (67). These authors found that dopamine $\mathrm{D}_{2}$ receptors in the hippocampus were associated with frontal lobe functions as executive functions. Therefore, the deficits observed in the present study may have been due to the actions of sulpiride elsewhere in the brain, e.g., hippocampus or striatal dopamine $\mathrm{D}_{2}$ receptors. Thus, the hippocampus-prefrontal interaction or fronto-striatal-thalamic circuit may be assumed as the sites of action of dopamine $\mathrm{D}_{2}$ receptor modulation of false memories. Further studies are clearly necessary to elucidate these issues.

Moreover, dopamine participates in decision-making processes, particularly response selection in specific circuits in which the dorsal striatum is involved with reward-related actions (45). Failures in this process may have contributed in the generation of false memories.

In the present study, sulpiride did not affect remembered emotional and non-emotional stimuli but increased false recognition only for emotionally charged items (positive and negative) and not neutral ones. This suggests that the dopaminergic system plays a role in emotional aspects of stimuli processing, more specifically through emotional valence modulating trace memory strength through the amygdala. Evidence that dopamine modulates the response of the human amygdala to sensory information was found in an fMRI study of Parkinson's disease (46). In this neuroimaging study, a robust bilateral amygdala response to fearful stimuli (faces) was observed in the control group, but this response was absent in patients during the hypodopaminergic state. Consonant with this idea, the SAM results of the present study revealed a change in the subjective judgment of the pleasure dimension of blocks (sex/disfigured faces).

The current SAM results also revealed a change in subjective judgment of arousal (mutilated bodies). Arousal has the capacity to modulate memory at many stages of stimuli processing including perception, encoding, and retrieval, playing a critical role in memory by regulating the focus of attention and consolidation (68). Studies with animals have revealed that the amygdala is the key structure for increased memory dependent on the hippocampus during arousal events $(69,70)$. A recent study suggested a functional role of $\mathrm{D}_{1}$ and $\mathrm{D}_{2}$ dopamine receptors in the overall potentiation of amygdala response to emotional loaded stimuli in humans (71).

The dopamine potentiates the amygdala response to emotionally loaded stimuli by two ways: (1) increasing the excitatory sensorial input (through dopamine $\mathrm{D}_{2}$ receptors stimulation) and at the same time, it (2) attenuates the inhibitory input from the prefrontal cortex through dopamine $\mathrm{D}_{1}$ receptor stimulation. In addition, the salient stimulus (emotionally loaded) increases dopamine concentration in basolateral amygdala and thus the local neuronal excitability (through dopamine $\mathrm{D}_{2}$ receptors) (47). Thus, based on that, the current results may indicate that sulpiride oral administration increased false recognition by reducing the distinctiveness of emotionally loaded stimuli.

The present study is limited by the small sample size, although efforts were taken to control the similarity of the groups (wellmatched according to age, BMI, intelligence, mood baseline, and years of study) at the beginning of trial. Individual variability in response to the drug and the subjective effects cannot be ignored. Another limitation to be considered is that both DRM and DRM-IAPS tasks were applied in laboratory conditions that only partially represent real life, as autobiographical memories are much more complex and include a whole recollection of an event (personal relevance, emotional salience, social context, and perceptual details that differ among people) (56). Nevertheless, DRM illusions are considered indicative of false memory and thus may be representative of autobiographical memory $(6,26,56,72-74)$. Future studies might address the role of dopaminergic neurotransmission in false memory on each single memory stage (encoding, consolidation, or retrieval).

To summarize, we envisage two mechanisms to explain the increased false memories of the sulpiride group, one involving working memory/executive functions through corticostriatal as well as hippocampus-prefrontal $\mathrm{D}_{2}$ dopaminergic modulation $(67,75)$ and the other through $\mathrm{D}_{2}$ dopaminergic modulation of the response of the amygdala to emotionally loaded stimuli (43, $47,71)$. These possible mechanisms fit quite well the two-process 
view of the causes of false memories, the activation/monitoring failures $(7,56)$.

\section{AUTHOR CONTRIBUTIONS}

All the authors contributed substantially to the planning of theoretical interpretation and writing the manuscript. JG was the psychiatrist responsible for the clinical trial. RG was responsible for performance of the experiment, having applied all the tests to the subjects with collaboration of RR. AS collaborated in planning and statistical analysis. LC and OB helped with interpretation of data and revising the manuscript.

\section{REFERENCES}

1. Conway M, Collins A, Gathercole S, Anderson S. Recollections of true and false autobiographical memories. J Exp Psychol Gen (1996) 125:69-95. doi:10.1037/0096-3445.125.1.69

2. Barclay C, DeCooke P. Ordinary everyday memories: some of the things of which selves made. In: Neisser U, Winograd E, editors. Remembering Reconsidered: Ecological and Traditional Approaches to the Study of Memory. New York: Cambridge University Press (1998). p. 91-125.

3. Tulving E. Elements of Episodic Memory. Oxford: Clarendon (1983).

4. Lindsay D. Contextualizing and clarifying criticisms of memory work in psychotherapy. Conscious Cogn (1994) 3:426-34. doi:10.1006/ccog.1994.1024

5. Eisen M, Quas J, Goodman G. Memory and suggestibility in the forensic interview. In: Eisen M, Quas J, Goodman G, editors. Processes Affecting Accuracy and Distortion in Memory: An Overview. New Jersey: Lawrence Erlbaum (2002).

6. Clancy S, Schacter D, McNally R, Pitman RK. False recognition in women reporting recovered memories of sexual abuse. Psychol Sci (2000) 11:26-31. doi:10.1111/1467-9280.00210

7. Roediger $\mathrm{H}, \mathrm{McDermott} \mathrm{K}$. Creating false memories: remembering words not presented on lists. J Exp Psychol Learn Mem Cogn (1995) 21:803-14. doi:10.1037/0278- 7393.21.4.803

8. Roediger H, Watson J, McDermott K, Gallo D. Factors that determine false recall: a multiple regression analysis. Psychon Bull Rev (2001) 8:385-407. doi:10.3758/BF03196177

9. Lang P, Bradley M, Cuthbert B. International Affective Picture System (IAPS): Affective Ratings of Pictures and Instruction Manual. Gainesville, FL: University of Florida (2008).

10. Ribeiro R, Pompéia S, Bueno O. Comparison of Brazilian and American norms for the International Affective Picture System (IAPS). Revista Brasileira de Psiquitaria (2005) 27:208-15. doi:10.1590/S1516-44462005000300009

11. Pinto L, Feijó L, Stein L. Creation of sets of associated emotionally-evocative pictures using the International Affective Picture System. Revista de Psiquiatria do Rio Grande do Sul (2011) 33:48-54. doi:10.1590/S0101-81082011005000005

12. Lang P. Behavioral treatment and bio-behavioral assessment: computer applications. In: Sidowski JB, Johnson JH, Williams TA, editors. Technology in Mental Health Care Delivery Systems. Norwood, NJ: Ablex (1980). p. 119-137.

13. Kensinger E. Remembering emotional experiences: the contribution of valence and arousal. Rev Neurosci (2004) 15:241-51. doi:10.1515/ REVNEURO.2004.15.4.241

14. Abrisqueta-Gomez J, Bueno O, Oliveira M, Bertolucci P. Recognition memory for emotional pictures in Alzheimer patients. Acta Neurol Scand (2002) 105:51-4. doi:10.1034/j.1600-0404.2002.00035.x

15. Cahill L, McGaugh J. A novel demonstration of enhanced memory associated with emotional arousal. Conscious Cogn (1995) 4:410-21. doi:10.1006/ ccog. 1995.1048

16. Hamann S. Cognitive and neural mechanisms of emotional memory. Trends Cogn Sci (2001) 5:394-400. doi:10.1016/S1364-6613(00)01707-1

17. McGaugh J. The amygdala modulates the consolidation of memories of emotionally arousing experiences. Annu Rev Neurosci (2004) 27:1-28. doi:10.1146/ annurev.neuro.27.070203.144157

\section{ACKNOWLEDGMENTS}

We appreciate the collaboration of Prof. Lillian Stein for furnishing the DRM and DRM-IAPS materials.

\section{FUNDING}

This research and the preparation of the manuscript were supported by the Associação Fundo de Incentivo à Pesquisa (AFIP), Conselho Nacional de Desenvolvimento Científico e Tecnológico $(\mathrm{CNPq})$, and Fundação de Amparo à Pesquisa do Estado de São Paulo (FAPESP). OB is a Research Scholarship CNPq level 1A.

18. Kensinger E, Corkin S. Memory enhancement for emotional words: are emotional words more vividly remembered than neutral words? Mem Cognit (2003) 31:1169-80. doi:10.3758/BF03195800

19. Kensinger E, Corkin S. The effects of emotional content and aging on false memories. Cogn Affect Behav Neurosci (2004) 4:1-9. doi:10.3758/ CABN.4.1.1

20. Cahill L, McGaugh J. Mechanisms of emotional arousal and lasting declarative memory. Trends Neurosci (1998) 21:294-9. doi:10.1016/ S0166-2236(97)01214-9

21. Ochsner K. Are affective events richly recollected or simply familiar? The experience and process of recognizing feelings past. J Exp Psychol Gen (2000) 129:242-61. doi:10.1037/0096-3445.129.2.242

22. Pesta BJ, Murphy MD, Sanders RE. Are emotionally charged lures immune to false memory? J Exp Psychol Learn Mem Cogn (2001) 27:328-38. doi:10.1037/0278-7393.27.2.328

23. Brainerd C, Stein L, Silveira R, Rohenkohl G, Reyna V. How does negative emotion cause false memories? Psychol Sci (2008) 19:919-25. doi:10.1111/j.1467-9280.2008.02177.x

24. Maratos E, Allan K, Rugg M. Recognition memory for emotionally negative and neutral words: an ERP study. Neuropsychologia (2000) 38:1452-65. doi:10.1016/S0028-3932(00)00061-0

25. Gallo D, Foster K, Johnson E. Elevated false recollection of emotional pictures in young and older adults. Psychol Aging (2009) 24:981-8. doi:10.1037/ a0017545

26. McNeely H, Dywan J, Segalowitz S. ERP indices of emotionality and semantic cohesiveness during recognition judgments. Psychophysiology (2004) 41:117-29. doi:10.1111/j.1469-8986.2003.00137.x

27. Huron C, Servais C, Danion J. Lorazepam and diazepam impair true, but not false, recognition in healthy volunteers. Psychopharmacology (2001) 155:204-9. doi:10.1007/s002130100683

28. Mintzer M, Griffiths R. Acute effects of triazolam on false recognition. Mem Cognit (2000) 28:1357-65. doi:10.3758/BF03211836

29. Garfinkel S, Dienes Z, Duka T. The effect of alcohol and repetition at encoding on implicit and explicit false memories. Psychopharmacology (2006) 188:498-508. doi:10.1007/s00213-006-0480-6

30. Milani R, Curran H. Effects of a low dose of alcohol on recollective experience of illusory memory. Psychopharmacology (2000) 147:397-402. doi:10.1007/ s002130050008

31. Mintzer M, Griffiths R. Alcohol and false recognition: a dose-effect study. Psychopharmacology (2001) 159:51-7. doi:10.1007/s002130100893

32. Mintzer M, Griffiths R. Acute dose-effects of scopolamine on false recognition. Psychopharmacology (2001) 153:425-33. doi:10.1007/s002130000592

33. Ballard M, Gallo D, de Wit H. Psychoactive drugs and false memory: comparison of dextroamphetamine and delta-9-tetrahydrocannabinol on false recognition. Psychopharmacology (2012) 219:15-24. doi:10.1007/ s00213-011-2374-5

34. Floresco S, Mayar O. Mesocortical dopamine modulation of executive functions: beyond working memory. Psychopharmacology (2006) 188:567-85. doi:10.1007/s00213-006-0404-5

35. Luciana M, Depue R, Arbisi P, Leon A. Facilitation of working memory in humans by a D2 dopamine receptor agonist. J Cogn Neurosci (1992) 4:58-67. doi:10.1162/jocn.1992.4.1.58 
36. Mehta M, Manes F, Magnolfi G, Sahakian B, TW R. Impaired set-shifting and dissociable effects on tests of spatial working memory following the dopamine D2 receptor antagonist sulpiride in human volunteers. Psychopharmacology (2004) 176:331-42. doi:10.1007/s00213-004-1899-2

37. Kemppainen N, Laine M, Laakso M, Kaasinen V, Nagren K, Vahlberg T, et al. Hippocampal dopamine D2 receptors correlate with memory functions in Alzheimer's disease. Eur JNeurosci (2003) 18:149-54. doi:10.1046/j.1460-9568.2003.02716.x

38. Knecht S, Breitenstein C, Bushuven S, Wailke S, Kamping S, Flöel A, et al. Levodopa: faster and better word learning in normal humans. Ann Neurol (2004) 56:20-6. doi:10.1002/ana.20125

39. Montoya A, Lal S, Menear M, Duplessis E, Thavundayil J, Schmitz $\mathrm{N}$, et al. Apomorphine effects on episodic memory in young healthy volunteers. Neuropsychologia (2008) 46:292-300. doi:10.1016/j. neuropsychologia.2007.07.012

40. Rammsayer T, Rodewald S, Groh D. Dopamine-antagonistic, anticholinergic, and GABAergic effects on declarative and procedural memory functions. Cogn Br Res (2000) 9:61-71. doi:10.1016/S0926-6410(99)00045-2

41. Wittmann B, Schott B, Guderian S, Frey J, Heinze H, Duzel E. Reward-related FMRI activation of dopaminergic midbrain is associated with enhanced hippocampus-dependent long-term memory formation. Neuron (2005) 45:459-67. doi:10.1016/j.neuron.2005.01.010

42. Nieoullon A. Dopamine and regulation of cognition and attention. Prog Neurobiol (2002) 67:53-83. doi:10.1016/S0301-0082(02)00011-4

43. Rosenkranz J, Grace A. Dopamine attenuates prefrontal cortical suppression of sensory inputs to the basolateral amygdala of rats. J Neurosci (2001) 21:4090-103.

44. Seamans J, Yang C. The principal features and mechanisms of dopamine modulation in the prefrontal cortex. Prog Neurobiol (2004) 74:1-57. doi:10.1016/j. pneurobio.2004.10.002

45. Balleine B, Delgado M, Hikosaka O. The role of the dorsal striatum in reward and decision-making. JNeurosci (2007) 27:8161-5. doi:10.1523/ JNEUROSCI.1554-07.2007

46. Tessitore A, Hariri A, Fera F, Smith W, Chase T, Hyde T, et al. Dopamine modulates the response of the human amygdala: a study in Parkinson's disease. J Neurosci (2002) 22:9099-103.

47. Rosenkranz J, Grace A. Cellular mechanisms of infralimbic and prelimbic prefrontal cortical inhibition and dopaminergic modulation of basolateral amygdala neurons in vivo. J Neurosci (2002) 22:324-37.

48. Raven J. Standard Progressive Matrices. Oxford: Oxford Psychologists Press (1997).

49. Biaggio A, Natalicio L. Manual para o inventário de ansiedade traço-estado (IDATE). Rio de Janeiro: Centro Editor de Psicologia Aplicada (CEPA) (1979).

50. Spielberger C, Gorsuch R, Lushene R, Vagg P, Jacobs G. Manual for the StateTrait Anxiety Inventory. Palo Alto, CA: Consulting Psychologists Press (1983).

51. Wiesel F, Alfredsson G, Ehrnebo M, Sedvall G. The pharmacokinetics of intravenous and oral sulpiride in healthy human subjects. Eur J Clin Pharmacol (1980) 17:385-91. doi:10.1007/BF00558453

52. Wechsler D. Manual for Wechsler Memory Scale - Revised. San Antonio: The Psychological Corporation (1987).

53. Deese J. On the prediction of occurrence of particular verbal intrusions in immediate recall. J Exp Psychol (1959) 58:17-22. doi:10.1037/h0046671

54. Stein L, Feix L, Rohenkohl G. Methodological advances in false memory research: development and norming of DRM procedure. Psicologia: Reflexão e Crítica (2007) 19:166-76. doi:10.1590/S0102-79722006000200002

55. Ballard M, Gallo D, de Wit $\mathrm{H}$. Amphetamine increases errors during episodic memory retrieval. JClin Psychopharmacol (2014) 34:85-92. doi:10.1097/ JCP.0000000000000039

56. Gallo D. False memories and fantastic beliefs: 15 years of the DRM illusion. Mem Cognit (2010) 38:833-48. doi:10.3758/MC.38.7.833

57. Cohen J. Statistical Power Analysis for the Behavioral Sciences. New Jersey: Lawrence Erlbaum (1988).

58. Pierce C, Block R, Aguinis H. Cautinionary notes on reporting eta-squared values from multifactor ANOVA designs. Educ Psychol Meas (2004) 64:916-24. doi:10.1177/0013164404264848

59. Howe M, Garner S, Threadgold E, Ball L. Priming analogical reasoning with false memories. Mem Cognit (2015) 43:879-95. doi:10.3758/s13421-015-0513-7
60. Sawaguchi T, Goldman-Rakic P. D1 dopamine receptors in prefrontal cortex: involvement in working memory. Science (1991) 251:947-50. doi:10.1126/ science. 1825731

61. Wang M, Vijayraghavan S, Goldman-Rakik P. Selective D2 receptor actions on the functional circuitry of working memory. Science (2004) 303:853-6. doi:10.1126/science. 1091162

62. Abi-Dargham A, Mawlawi O, Lombardo I, Gil R, Martinez D, Huang Y, et al. Prefrontal dopamine D1 receptors and working memory in schizophrenia. J Neurosci (2002) 22:3708-19.

63. Müller U, Yves von Cramon D, Pollmann S. D1- versus D2-receptor modulation of visuospatial working memory in humans. J Neurosci (1998) 18:2720-8.

64. Ahveninen J, Kähkönen S, Tiitinen H, Pekkonen E, Huttunen J, Kaakkola S, et al. Suppression of transient $40-\mathrm{Hz}$ auditory response by haloperidol suggests modulation of human selective attention by dopamine D2 receptors. Neurosci Lett (2000) 292:29-32. doi:10.1016/S0304-3940(00)01429-4

65. Coull J, Sahakian B, Middleton H, Young A, Park S, McShane R, et al. Differential effects of clonodine, haloperidol, diazepam, and tryptophan depletion on focused attention and attentional search. Psychopharmacology (1995) 121:222-30. doi:10.1007/BF02245633

66. Kähkönen S, Ahveninen J, Jääskeläinen I, Kaakkola S, Näätänen S. Effects of haloperidol on selective attention. Neuropsychopharmacology (2001) 25:498-504. doi:10.1016/S0893-133X(01)00255-X

67. Takahashi H, Kato M, Hayashi M, Okubo Y, Takano A, Ito H, et al. Memory and frontal lobe functions; possible relations with dopamine D2 receptors in the hippocampus. Neuroimage (2007) 34:1643-9. doi:10.1016/j. neuroimage.2006.11.008

68. LaBar K, Phelphs E. Arousal-mediated memory consolidation: role of the medial temporal lobe in humans. Psychol Sci (1998) 9:490-3. doi:10.1111/1467-9280.00090

69. McGaugh J, Introini-Collison I, Cahill L, Kim M, Liang K. Involvement of the amygdala in neuromodulatory influences on memory storage. In: Aggleton JP, editor. The Amygdala: Neurobiological Aspects of Emotion, Memory, and Mental Dysfunction. New York: Wiley-Liss (1992). p. 431-51.

70. Packard M, Cahill L, McGaugh J. Amygdala modulation of hippocampal-dependent and caudate nucleus-dependent memory processes. Proc Natl Acad Sci U S A (1994) 91:8477-81. doi:10.1073/pnas.91.18.8477

71. Takahashi H, Takano H, Kodaka F, Arakawa R, Yamada M, Otsuka T, et al. Contribution of dopamine D1 and D2 receptors to amygdala activity in human. J Neurosci (2010) 30:3043-7. doi:10.1523/JNEUROSCI.5689-09.2010

72. Clancy S, McNally R, Schacter D, Lenzenweger M, Pitman R. Memory distortion in people reporting abduction by aliens. J Abnorm Psychol (2002) 111:455-61. doi:10.1037/0021-843X.111.3.455

73. Geraerts E, Smeets E, Jelicic M, van Heerden J, Merckelbach H. Fantasy proneness, but not self-reported trauma is related to DRM performance of women reporting recovered memories of childhood sexual abuse. Conscious Cogn (2005) 14:602-12. doi:10.1016/j.concog.2005.01.006

74. Platt R, Lacey SC, Iobst A, Finkelman D. Absorption, dissociation, and fantasy-proneness as predictors of memory distortion in autobiographical and laboratory-generated memories. Appl Cogn Psychol (1998) 12:S77-89. doi:10.1002/(SICI)1099-0720(199812)12:7<S77::AID-ACP601>3.0.CO;2-C

75. Takahashi H, Kato M, Takano H, Arakawa R, Okumura M, Otsuka T, et al. Differential contributions of prefrontal and hippocampal dopamine D1 and D2 receptors in human cognitive functions. J Neurosci (2008) 28:12032-8. doi:10.1523/JNEUROSCI.3446-08.2008

Conflict of Interest Statement: The authors declare that the research was conducted in the absence of any commercial or financial relationships that could be construed as a potential conflict of interest.

Copyright (c) 2016 Guarnieri, Ribeiro, de Souza, Galduróz, Covolan and Bueno. This is an open-access article distributed under the terms of the Creative Commons Attribution License (CC BY). The use, distribution or reproduction in other forums is permitted, provided the original author(s) or licensor are credited and that the original publication in this journal is cited, in accordance with accepted academic practice. No use, distribution or reproduction is permitted which does not comply with these terms. 